\section{Normal, internationales und nationales}

C. Vidal ${ }^{1}$ und W.-R. Külpmann ${ }^{2}$

${ }^{1}$ Landeskriminalamt Niedersachsen, Dezernat 53 „Chemie“, Hannover, Deutschland

${ }^{2}$ Hannover, Deutschland

Englischer Begriff international and national measurement standard

Definition - Normal, das entweder auf internationaler Ebene von den Unterzeichnern eines Abkommens für welt- weite Benutzung anerkannt wurde oder das durch eine nationale Behörde anerkannt ist, in einem Land oder einer Volkswirtschaft als Grundlage dafür zu dienen, Größenwerte anderen Normalen für die betreffende Größenart zuzuordnen (Brinkmann 2012). Für Anmerkungen s. Literatur.

\section{Literatur}

Brinkmann B (2012) Internationales Wörterbuch der Metrologie (VIM) Deutsch-englische Fassung. ISO/IEC-Leitfaden 99:2007, 4. Aufl. Beuth-Verlag, Berlin 